indeed rather worse. I then hesitated between advising suggestion treatment and injection of the Gasserian ganglion. He would not have the former, and, again against my better judgement, I injected him, this time through the foramen ovale, producing total and permanent fifth nerve anaesthesia. His eye and cornea fortunately gave no trouble, but he was now even more complaining of the pain, and he therefore went to see a surgeon regarding gasserectomy, who, however, refused to do the operation when he found the fifth nerve area totally anaesthetic. Baulked in this, he went to yet another surgeon; who operated to remove his ganglion; but the last I heard of him was that he was complaining even more of pain.

The moral of this tale is that it is unwise to attempt any form of surgical treatment for psychalgias, the pain is apt to get worse, or spread to another area, and once an operation has been performed, it is most difficult for another practitioner to sift the real from the false and to make a diagnosis.

\section{A CASE OF PYOCELE OF THE FRONTAL SINUS.}

J. A. GIBB, M.B., M.CH.,

HONORARY SURGEON, KENT COUNTY HOSPITAL FOR DISEASES OF IEY, FAR, NOSE, AND THROAT, MAIDSTONE.

ON May 18th, 1921, I was asked by Mr. Potts, ophthalmic surgeon to this hospital, to examine a patient, a married woman, aged 57, for frontal sinusitis. She had a slight swelling at the inner canthus of the left eye, and complained of some "pricking in the left eye," but not of headache or any other subjective symptom.

The swe!ling was firm and could not be pressed awa.y. Intranasal examination showed no discharge on either side; the mucous membrane was quite normal in appear. ance and there was no enlargement of the turbinate bones. The post-nasal space was also quite clear of any discharge. Transillumination showed both frontal sinuses clear and of about normal size; the maxillary antrum was also clear; there was no history of a blow. My report was that the frontal ethmoid and maxillary sinuses were unaffected.

'Three months after this the patient was admitted into hospital with a compressible sivelling on the left frontal sinus. The house-surgeon, Mr. Reed Hill, needled it and got pus. There were no subjective symptoms such as headache, etc.; the temperature was negligible. The eyeball was pushed downwards and outwards, with swelling of the soft tissues of the upper eyelid and inner angle of the orbit.

Operation.

I operated as soon as the patient could be got ready, making an incision along the eyebrow; there was an immediate gush of odourless reddish muco-pus. A gloved finger was inserted into the cavity, which was felt to be unusually large. I therefore made a further incision at right angles to the original at its inner angle, going well up the forehead; the Hap was turned inner angle, going well up the forehead; the flap was turne

pwards, the cavity stwabbed dry, and all bleeding arrested. sinus, with the exception of a thin pliable piece of bone adherent to the flap, was absorbed. The floor (except for a small plate of bone over the orbit), the posterior wall, and the septum between the two sinuses were also absorbed, so that the right frontal sinus could easily be explored. Portions of dura mater were missing, and brain substance, looking red and intlamed, was exposed. A probe could be passed on either side into the nose ; the posterior ethmoid cells were absorbed. The fronto-nasal duct could not be made out, and the probe could be passed down to the loop of the post-nasal space, the mucoperiosteum everywhere being intact, except where the orbital periosteum everywhe hor the plate had been absorbed; here the probe passed in to the cheek The sagittal sinus was intact, but the whole of the left frontal obe of the brain was completely exposed and, if it had been The wound was sutured with the exception of its outer and The wound was sutured with the

Recovery was gradual, and the temperature and pulse negligible thronghout until, at the end of three weeks, a pocke of pus, quite different from the original infection, formed unde the scalp at the inner angle of the original incision and extended down to the cheek. This was opened, gently scraped, and swabbed out with bypochlorite solution. The patient is now quite well.

I deemed it unnecessary and inadvisable to open up any communication with the nasal cavities, as I felt that the cavity would in all probability become filled with fibrous tissue.

The case was shown at the local Branch of the British Medical Association, and I expressed the opinion then that the condition was a mucocele of the frontal sinus which had become infected. The recent Hunterian Lecture by Mr. Howarth, published in the Lancet of October 8th, has impressed me with the fact that the condition is not as uncommon as I at first deemed it to be; nevertheless the publication of this case may be of some interest.

The following details of the eye condition, as recorded by Mr. Potts, were supplied to me by Mr. Reed Hill :

The patient attended hospital on May 14th, complaining of slight discomfort behind the left eye. On examination, $R$. vision $=6 / 6$, L. vision $=6 / 12$, no hypermetropia; a small swelling was felt below the left supraorbital notch ; some slight proptosis was present, and displacement of eye downwards and outwards, was present, and displacement of eye downwards and outwards, but no diplopia. Exar

On re-examination four months later, the eye was observed to On re-examination four months later, the eye was observed to
have returned practically to its normal position. The proptosis had disappeared, and there was very slight displacement of the eye downwards, the level of the left pupil being about two millimetres below that of the right. Fundus, optic disc and media were quite normal. It was found that the patient had an error of refraction which when corrected gave R.V. $\bar{c}+1.25 \mathrm{D}$ cyl. axis vert. $=6 / 6 ; \mathrm{L}$.V. $\overline{\mathrm{c}}+1.25 \mathrm{D}$ cyl. axis $\nvdash 70^{\circ}=6 / 9$. On testing for heterophoria the left image was fonnd to be situated above and to the right of the right image, but they were approximately fused by a $12 \Delta$ prism base upwards and inwards. The extrinsic muscles appeared not to have been affected, as there was no limitation of movement of the eye. The fields showed no contraction, nor were there any scotomata to be made out with either white or colours.

\section{SU'TURE OF SEVERED MEDIAN NERVE, WI'TH RAPID RECOVERY OF FUNCTION.}

BY

EDGAR WIRTH, M.D.MALTA, ESSEX COUNTY HOSPITAL.

A Boy, aged 14, on May 28th, 1921, thrust his arm through a window pane, severing the internal and part of the external belly of the biceps and coraco-brachialis muscles, the brachial artery and vein, and the internal cutaneous and median nerves. First aid was luckily at hand, a tourniquet was applied and the boy sent to the hospital.

Examination of function revealed complete loss of power in all the muscles, and loss of epicritic, protopathic and deep sensibility in the area supplied by the median nerve. The latter was severed on bec de flute without irregular tags.

I ligatured the brachial artery and vein and freed the median nerve at the proximal and distal ends. By means of a fine suture of chromicized catgut exact adaptation of the ends was suture of chromicized catgut exact adaptation of the ends was aimed at, with the view of bringing each proximal fibre in contact with its own distal fibre, as far as could be expected. This was obtained by rotating the ends of the divided nerve on their axes. A zigzag suture of catgut was then introduced all round the nerve, taking into each stitch-loop only the sheath, and no nerve tissue, and in such a manner that all the longitudinal threads lay on the outer su
For this purpose the sheath was transfixed twice at each bend of the gut, in a transverse direction thereby minimizing the danger of cutting through.

Through the retraction of the sheath, which ensues in such cases, the protruding nerve fibres tended to slip out from between the bars of this cylindrical fence of catgut, and had to be pushed back with a probe. I did not find this method of suiuring difficult, nor did it take much time. I believe that the noninclusion of nerve tissue in the stitch and in the complete retention of the prolapsing fibres by numerous threads of catgut all round, which at the same time secured accurate adaptability of the ends, may have a lot to do with the rapid restoration of function.

A glove drain was left in the depth of the wound, the arm put up in a flexed position and at complete rest on a pillow. Healing was uneventful.

Two days after the operation I was surprised to find that the patient showed distinct improvement in some of the movements controlled by the median nerve, as, for instance, better flexion at the wrist, much better pronation of the forearm, less impairment of opposition of the thumb, and less difficulty in abduction of the thumb. There was, however, still inability to flex the terminal phalanges of thumb and index finger.

At the end of six weeks there was almost complete return of normal muscle power, the grip remaining somewhat weak. Sensation showed little improvement. For 
three weeks after the liealing of the wound a palmar splint and a sling were worn to ensure complete rest. Then massage and galvanism were started. Two months after the original injury trophic changes were noticed in the skin of the thumb, index, and middle fingers, consisting of an exfoliation of the outer layers of the skin. At the present time the skin of the affected fingers is perfectly normal.

On October 19th, 1921, comparative examination of the right and left upper limbs showed no difference in flexion of wrist, pronation of forearm, opposition and abduction of the thumb. There was a satisfactory grip, but still difficulty in the flexion of the terminal phalanx of index and, to a lesser extent, of that of the thumb. Deep sensibility was present all over the area of distribution of the median nerve. Epicritic and protopathic sensibilities were wanting only over the index finger.

To Dr. Chichester I wish to express my thanlis for allowing me to publish this case.

\section{Atentaranda: \\ MEDICAL, SURGICAL, OBSTETRICAL.}

\section{THE SCOPE OF SURGERY IN GENITO-URINARY 'TUBERCULOSIS.}

Is a leading article published on November 5th emphasis is laid on the generally accepted view that the only hope of dealing with a tuberculous lesion of the kidney is by nephrectomy. I have good reason for knowing that surgeons are impatient of even considering any other method, although at least one great authority states that renal tuberculosis almost always escapes detection during the period when a nephrectomy offers the greatest chance of success, and Bernstein and others do not hesitate to assert that great success has followed treatment by tuberculin injections.

'The following case may not be without interest:

Captain D. consulted me in October, 1913, with a history of repeated attacks of haematuria. The first attack was in March, 1913, when it was accompanied with sharp, burning pain in the urethra and lumbar region. The blood disappeared in two urethra and lumbar region. The blood disappeared in two days, leaving a dull pain in the left lumbar region. This pain phthisis, and be himself had had "consumption of the bowels" phthisis, and he himself had had "consumption of the bowels"
whenta child. There was no history of syphilis, and an $x$-ray whena chila. There was no history of syphilis, and an $x$-ray
phatograph of the lumbar region was negative. In April the phatograph of the lumbar region was negative. In April the urine had been most carefully examined elsewhere, the report Cystoscopic examination by specialists in London had shown a perfectly normal bladder and urethra, and the patient had been recommended to visit Contrexéville, as it was thought that his symptoms were the result of irritation by oxalate crystals. While at Contrexéville the pain began to radiate down the left leg, and as no relief was obtained he returned home and finally came uuder my care.

I found him highly nervous and complaining of much pain in the lumbar region and of frequent and painful urination. He looked pale and worn. The left testicle was atrophied, the looked pale and worn. The left testicle was atrophied, the result of an orchitis of nine years earlier. Von Pirquet's test
was strongly positive. Accordingly, two days later, I gave him was strongly positive. Accordingly, two days later, I gave him a further test with old tuberculin, when again the result was very positive, with both local and general reaction. On
November 7 th the bacteriological report by Dr. Galt of the November 7th the bacteriological report by Dr. Galt of the plentiful and in clumps, many blood cells and few pus cells. No casts or crystals."

On November 11th injections of tuberculin were commenced with a dose of $1 / 50,000 \mathrm{mg}$. bacillary emulsion. There was a very slight local reaction. On November 20 th a dose of $1 / 20,000 \mathrm{mg}$. was given ; on the $24 \mathrm{th}, 1 / 10,000 \mathrm{mg}$.; on the $27 \mathrm{th}$, $1 / 5,000 \mathrm{mg}$. ; on December 1st, 1/2,500 mg. ; on December 5th, $1 / 1,000 \mathrm{mg}$. By this time there was great general improvement, although there was complaint of "burning " over the region of the bladder, and some lumbar pain. The patient had put on no less than $7 \mathrm{lb}$. in weight. On December 9th, after a dose of no less than $7 \mathrm{lb}$. in weight. On December 9 th, after a dose of $1 / 500 \mathrm{mg}$. , there was considerable local reaction about thirty-six
hours after the injection. No further dose was given until the hours after the injection. No further dose was given until the
$16 \mathrm{th}$, when the dose of $1 / 500 \mathrm{mg}$. was repeated. On the 23rd, $16 \mathrm{th}$, when the dose of $1 / 500 \mathrm{mg}$. was repeated. On the 23rd, $1 / 500 \mathrm{mg}$. was again given ; and the patient was now much
improved. On the 27 th, the dose was $1 / 120 \mathrm{mg}$., and the patient, improved. On the 27 th, the dose was $1 / 120 \mathrm{mg}$., and the patient, although he still had some pain, expressed himself as feeling
very much better. On January 15th the patient had gained $10 \frac{1}{2}$ lb. since treatment began.

The next five doses were all 1/150 mg., as there had been slight general reaction after the dose of $1 / 120 \mathrm{mg}$. This was followed by four doses, at about the same intervals, of $1 / 100 \mathrm{mg}$. There was no reaction after any of these doses. The patient was looking and feeling exceedingly well, with entire absence of pain and good appetite. By desire of the patient a specimen was now sent to Shorncliffe for examination by the army wathorities, the report being: "Some pus cells, some renal authorities, the report being: "Some pus cells, some renal,
epithelium, one clump of tubercle bacilli, ffiteen in number." epithelium, one clump of tubercle bacilli, fifteen in number." I then gave him, at intervals of about four days, four doses of only. On March 11th a report was received both from the army authorities and from the Brighton pathologist that the urine was quite normal. On March 13th he was given a dose of $1 / 25 \mathrm{mg}$., resulting in a very slight local reaction. This dose was continued at weekly intervals up to the middle of May. The patient's weight was now $11 \mathrm{st}$. $9 \mathrm{lb}$., or $2 \mathrm{lb}$. heavier than he had ever been in his life before. On March 29th the report from Shorncliffe was: "No tubercle bacilli, but some pus cells." On May 16th the largest and last dose of the course pus cells." $116 \mathrm{mg}$., and there was no reaction. ing mg., and there was no reaction. The patient was now feeling exceedingly well, with perfect appetite and entire absence they had found only a few tubercle bacilli beaded.

The patient was sent away for three months into the country, The patient was sent away for three months into the country,
and on June 14th the Shorncliffe report was: "Tubercle bacilli and on June 14th the Shorncliffe report was: "Tubercle bacilli very scanty, two only seen. Some pus cells." On July lith
report said: "No tubercle bacilli, few pus and renal epithelium cells." On September 4th Shorncliffe reported: "Tubercle bacilli very scanty and beaded." On September 13th the patient wrote that he was feeling quite well, had no pain of any sort, and was quite certain that he could easily go back to duty. On September 18th Dr. Galt reported: "No tubercle bacilli, no pus, blood, or crystals," and on the 29th, "No blood, pus, or casts, culture sterile, no tubercle bacilli," with note, "Urine seems to be quite normal,"

The patient is still, I am informed, enjoying good health, and performing his usual army duties, and it seems to me that in this case, at any rate, the tuberculous lesion of the kidney was cured "otherwise than by nephrectomy." Hove. A. H. Copeman, M.D.

\section{ANAPHYLAXIS TO WASP VENOM.}

G. W., aged 51, a farm labourer, who had always previously enjoyed good health, was stung on the ear on August 13th, 1921. He fainted after the sting, felt very ill, and had to be helped home. The ear became swollen and eczematous, and a few days later slight enlargement of the cervical glands occurred. Ten days subsequently a generalized urticaria appeared, which was followed in three days by acute general exfoliative dermatitis; this lasted for a fortnight, leaving him debilitated, and causing enlargement of the heart and accentuation of the pulmonary second sound.

He appears to have been sensitized by a wasp sting eight years ago; on that occasion he felt faint and suffered from local swelling round the site of the sting for a few days. All his life he has had a very great horror of wasps, although not at all afraid of bees.

A point of medico-legal interest in connexion with the case is that he successfully claimed sickness benefit under the Workmen's Compensation Act.

Cheltenham.

J. Allyan Powell, M.D.

\section{OBSTRUCTED BREECH DELIVERY DUE TO} HYDROCEPHALUS AND SPINA BIFIDA.

On October 19th, 1921, a multipara, aged 44, was confined of her ninth child. Her previous continements had been apparently normal. One of us was in attendance, and on arrival found a breech presenting in the vagina. With a little trouble the feet were brought down, but no safe traction could produce further delivery. On the arrival of the other of us chloroform was administered, but for some minutes further traction was useless; a large head could be felt from the abdomen.

On further vaginal examination a tense "bag of fluid" could be felt high up on the dorsum of the foetus. The prospect of locked twins occurred to us, when further examination ruptured this " bag," and a large amount of serous fluid escaped. Now an irregular hollow, about 4 inches by 3 , was apparent in the back of the fetus, and by traction on this and the feet the child was delivered.

The child was dead, and was full time; it had a large lyydrocephalus, which apparently had collapsed and drained through the spinal opening; it was much deformed, the neck and several cervical vertebrae being undeveloped. The mother made an uninterrupted recovery.

Bentham, Lancaster.
A. J. Troughton, L.R.C.P. and S.Ed., J. F. Dow, M.D.Vict. 